\title{
A Service Station Location Model to Explore Prospects and Policies for Alternative Transport Fuels: A Case of CNG Distribution in Italy
}

\author{
Damiana Chinese, Piera Patrizio and Monica Bonotto
}

\begin{abstract}
CNG is an example of alternative gaseous fuel whose market development requires supply infrastructure (pipelines), refuelling stations and alternative vehicles to exist at the same time, which is known as the "chicken and egg dilemma". In this chapter, a case study of limited or locally nonexistent market development for $\mathrm{CNG}$ in an Italian frontier region is analyzed and a mixed integer non linear programming model is introduced to evaluate the effect of incentive measures envisaged by the regional government to foster refuelling station development. It is found that, taking an entrepreneurs' perspective of maximizing profits, even with substantial capital grants investors are more likely to choose higher demand areas, in spite of fiercer competition, rather than areas without stations. Subsidies should be more specifically targeted to critical areas to be efficient.
\end{abstract}

Keywords CNG filling stations - Compressed natural gas vehicles • Mixed integer non linear programming $\cdot$ Location mode

\section{Introduction}

The simultaneous existence of fuel supply chains, refuelling stations and alternative vehicles is required for a sustained adoption of alternative transport fuels. In particular, especially the introduction of new gaseous fuels, such as hydrogen, $\mathrm{CNG}$ or biogas, faces the challenge of attracting investors in refuelling stations to attain satisfactory refuelling service levels, so that, in turn, more customers find new gaseous fuels an attractive option and market develops [1].

D. Chinese $(\square) \cdot$ P. Patrizio $\cdot$ M. Bonotto

DIEGM, Dipartimento di Ingegneria Elettrica, Gestionale e Meccanica,

University of Udine, 33100 Udine, Italy

e-mail: Damiana.chinese@uniud.it 
This subject, which is known even in literature as "the chicken and egg dilemma", is investigated in few studies from either a modelling or an empirical perspective. Most empirical [1,2] or model based [3] studies are performed at a national or international scale, so they give substantial strategic insights but cannot be immediately used at the detailed, local planning level to guide the site and capacity definition of refuelling stations.

On the other hand, the use of operations research models for location planning of service stations is widely spread in literature. Most applications concern future hydrogen based supply chains [4-8], while a single example handling CNG refuelling stations is reported [9].

Upchurch and Kuby [10] present a review of models for optimal location of alternative-fuel stations and summarize three general approaches to locate refuelling stations optimally, i.e.:

- Variants of the p-median model, generally based on census data (about population and car ownership), which tend to and locate stations close to where people live, in harmony with empirical research demonstrating that consumers prefer to refuel near their homes [11].

- Traffic count or VMT methods, based on road traffic data, which tend to locate stations on several adjacent links of high volume freeways.

- Flow intercepting location models, which yield more realistic representations but require a data matrix of traffic flows from origins to destination, which is hardly available at some geographic scales.

For each of these approaches, several variants of objective functions could be conceived, but, to the best of our knowledge, competition factors such as the profitability of single service stations are seldom taken into account. Models focusing on intercepting flow allow to maximize revenues, while a least cost planning philosophy underpins variants of maximum covering algorithms (e.g. Bapna et al. [12]) and strategic planning models at supply chain level [13]. Profitability of service stations is considered implicitly in multicriteria approaches adopted by Frick et al. [9], who use utility models, and by Brey et al. [14], who develop an AHP model. Explicitly, profitability is incorporated in the objective function only by Hugo et al. [15], who deal with the strategic supply chain planning of hydrogen, particularly with refineries location planning, and by Bersani et al. [6], who aim at maximizing net present values of a network of hydrogen fuelling stations.

To overcome the chicken and egg dilemma, the profitability of service stations is, however, a key issue: empirical research has shown that, in cases of successful market penetration of alternative transport fuels, refuelling infrastructure mostly grew through private investment [2]. Therefore, understanding which options for technology, capacity and location planning would be most desirable for potential investors, who aim at maximizing their profits, allows to gain insight on the future evolution of alternative fuel distribution systems and on their chances to thrive or decline. 
This especially applies to the case of our concern, that is the development of CNG service stations in Friuli Venezia Giulia (FVG), an Italian region with about one million inhabitants located at the border with Austria and Slovenia. While the market penetration of CNG in Northern Italy is remarkable, reaching a market share of $2 \%$ of total cars statistics [16], and the number of service stations is generally expanding [17] in FVG the market share of CNG cars stops at $0.3 \%$. And only three refuelling stations exist, located in municipalities marked in black in the upper right miniature in Fig. 1, i.e. mostly in the Western part of the region. Historically, taxes on fuels have been significantly lower in neighbouring countries than in Italy, which makes refuelling abroad the cheapest option, especially for inhabitants living closer to Slovenia. To reduce the resulting flow of refuelling commuters, the regional government of FVG used to finance a system of pricing zones depending on distance to borders, which was modified in 2011 due to objections by the European Union on the grounds of distortion of economic competition between countries. The effectiveness of the discounts was often limited, especially in the first pricing zone (represented in medium gray and marked as F1 in the miniature map in Fig. 1).

This situation is a typical example of a "chicken and egg" dilemma, preventing investors from installing alternative fuel stations, especially in the bordering area. The regional government recently conceived some financial support measures for new CNG distribution stations, which were then stopped as a consequence of national and regional spending reviews. Our aim is to estimate the potential impact of the envisaged subsidies and to evaluate prospects for $\mathrm{CNG}$ in the area, by assessing the economical feasibility of expanding the distribution network in the examined region under current and potential circumstances. For this purpose, we analyzed factors affecting actual CNG demand in FVG as reported in Sect. 2 and developed a mixed integer linear programming model for identifying the optimal location, technology and capacity of CNG refuelling stations as shown in Sect. 3. Obtained results are discussed in Sect. 4.

\section{Factors Affecting Decisions on the Location of CNG Refueling Stations in Friuli Venezia Giulia}

To develop a location model accounting for profits of refuelling stations, potential sales should be estimated. Data on CNG consumption have been collected at regional level in FVG in recent years [18], but they are only available for a restricted time period (from 2007 to 2011) and at a regional aggregation level, so it is not possible to discriminate between sales at different sites. On the other hand, data on the determinants of fuel demand commonly recognized in literature $[2,19]$ are available at a more local level: gasoline prices between 2007 and 2010 are available at municipal level from studies on the zone tariff mechanism, the share of CNG vehicles is known at regional level since 2006 [16], at province level for the year 2009 (personal communication by Federmetano, 2012)and the number of total 


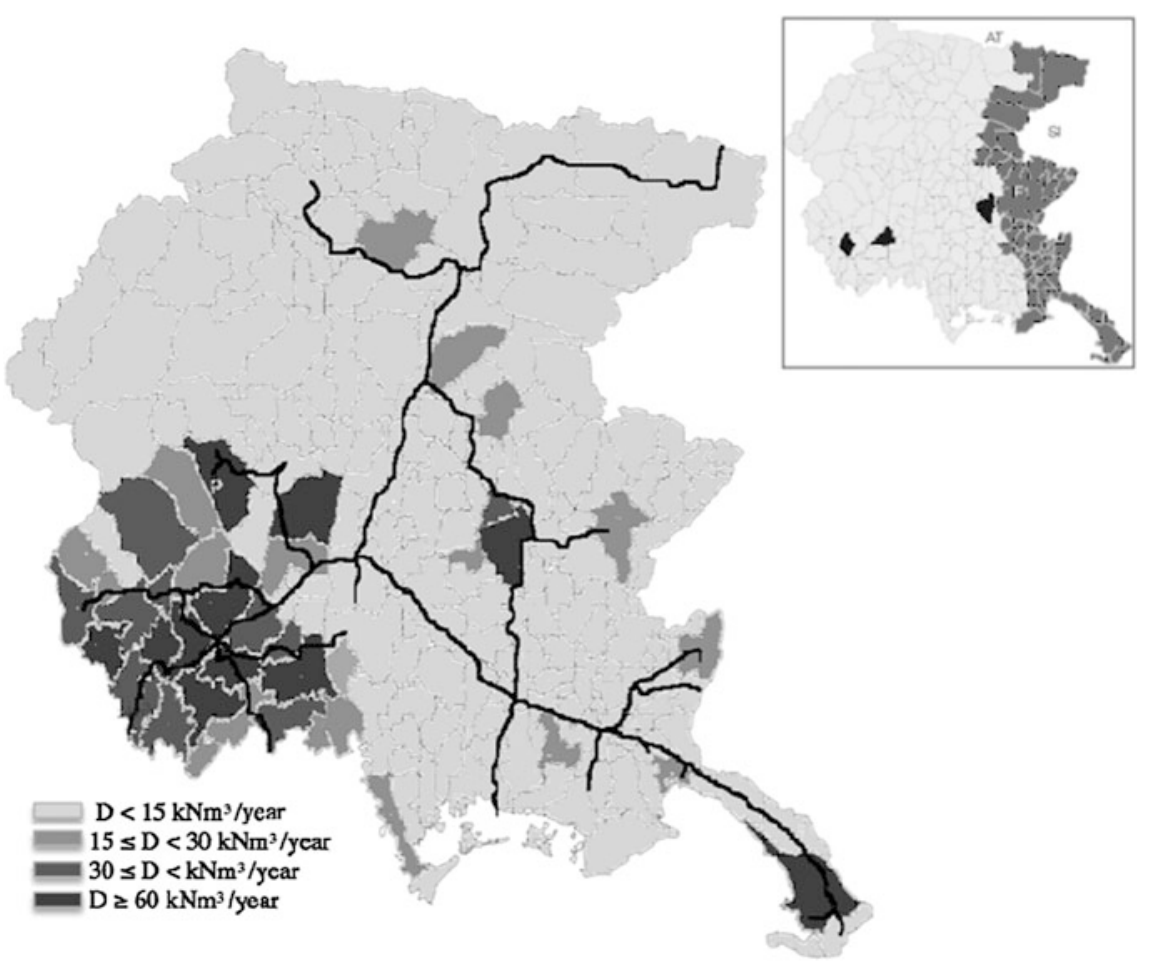

Fig. 1 Distribution of estimated CNG demand and factors affecting the location of CNG stations in FVG

vehicles is known at municipal level for the year 2009 (http://www. comuni-italiani.it/06/statistiche/veicoli.html). For this reason, we used national data to create static econometric models [20], in order to clarify the relation between the involved variables, then applied such models using local data and validated them at regional level by comparing estimated and real regional demand, calculating RMSEs in order to identify best fitting models. In this way, we formulated and tested several alternative models, both logarithmic and linear.

At the end, the best fits were obtained with the simple model expressed by Eq. (1):

$$
\mathrm{D}_{\mathrm{IT}}=1,27 \mathrm{~V}_{\mathrm{IT}}
$$

The obtained model has a coefficient of determination $\mathrm{R}^{2}=0.98$ and percent errors between $-11 \%$ and $+6 \%$ when estimating regional consumption for the years 2007-2011. Thus, we deduce that:

- The model can be used at least at regional level to make reasonable forecasts of demand; 
- The specific consumption of CNG per vehicle in FVG is aligned with national data;

- As the model is obtained by regression through the origin, also use at municipal level seems acceptable.

For this purpose, we will use data on the total number of vehicles available at municipal level for the year 2009 and weigh them by the share of CNG vehicles on total vehicles in the same year, available at province level, i.e. at an intermediate aggregation level between regional and municipal ones.

\subsection{The Impact of Distance from Slovenia on Demand of Gaseous Vehicle Fuels}

While we found that regional specific CNG demand per vehicle is aligned with national values, to apply the model at municipal level it would be desirable to understand how distance from Slovenia may affect CNG demand. While there are no data on CNG, we got data about LPG vehicles and LPG consumption at province level, provided by the Italian Ministry for Economic Development. LPG shares similar features with CNG in that it is a niche market fuel, alternative to gasoline and diesel oil, characterized by tax exemption and consequent lower prices and no zone tariff in FVG. By performing both a general stepwise linear regression and a partial correlation analysis to test the relationship between province LPG demand (D), number of vehicles (V) and province distance (T) from Slovenia, we concluded that factor $\mathrm{T}$ will almost disappear when controlling for $\mathrm{V}$. In other words, demand for LPG is affected by distance from Slovenia in that more alternative fuel vehicles are purchased in farthest municipalities from the border, whereas the average consumption per vehicle remains unaffected. We can assume CNG demand to behave similarly, and that, consequently, the coefficient in the model above does not need to be calibrated for the distance from the border, once the number of vehicles at local level is known. We can thus apply Eq. (1) to estimate demand at municipal level based on the total number of vehicles per municipality and the CNG vehicle share at province level, obtaining the main map in Fig. 1.

\subsection{How Closeness to Natural Gas Pipelines and Pressure Levels of Natural Gas Supply Affect Costs}

Figure 1 also shows the location of the natural gas high-pressure pipeline in FVG, which has a significant impact on effectiveness of CNG stations. In fact, the main element of a CNG station is a compressor plant, which elevates natural gas pressure from municipal distribution ( 4 bar) or gas pipeline (40 bar) levels to the 
high-pressure levels required for refueling (220 bar). Both compressor installation and operation costs are higher when connecting to low pressure (LP) infrastructure than to high pressure (HP) infrastructure, but while LP pipeline exists in every municipality considered as eligible location in this study, Fig. 1 shows that HP pipeline is only present in a limited number of municipalities. On the other hand, it should be observed that costs of connecting to LP infrastructure are generally lower than HP pipeline connection costs because distribution pipes are nowadays virtually present under every road, while HP pipeline are usually farther from urban centers. However, rather than incorporating such micro-location issues in an overall optimization model, possibly enhancing its complexity to a great extent, we preferred to preliminarily evaluate the impact of connection costs on annual equivalent costs of CNG stations based on cost data obtained from constructors for various plant capacities and found that connecting to the HP pipeline is the optimal solution when inequality 2 is verified, i.e.:

$$
D_{\text {pip }}(Q)<365 e^{0.002 Q}
$$

where $\mathrm{D}_{\text {pip }}$ is the distance from pipe, $\mathrm{D}_{\mathrm{be}}$ is break even distance and $\mathrm{Q}$ represents the given capacities of the refueling stations in $\mathrm{kNm}^{3} /$ year. It should be noticed that, according to the current market trends, it is unlikely that CNG-dedicated stations shall be built: capital costs considered here refer to the upgrade of existing fuel stations to distribute also CNG.

Given an average surface of municipalities of about $35 \mathrm{~km}^{2}$, an average number of 2.1 existing fuel stations per municipality and typical capacity ranges of refueling stations between 300 and $1000 \mathrm{kNm}^{3} /$ year, in our model we will assume that in municipalities served by HP pipeline it will be generally possible to find a fuel station to upgrade to $\mathrm{CNG}$ within the economical distance from the pipeline.

\subsection{Subsidies Foreseen by Friuli Venezia Giulia to Overcome the Chicken and Egg Dilemma}

In August 2010, in order to overcome the chicken and egg dilemma, a legislative decree has been issued by the regional government (L.R.14/2010), relating to subsidies' disbursement for CNG fuel stations establishment in the region. Such subsidies, supplied as outright grants, have a maximum value of $50 \%$ of the total construction expenditure, regardless of the location decision.

\section{Model Formulation}

The main goal of the model is to estimate whether and where entrepreneurs are likely to invest in CNG refuelling stations under current and prospective circumstances, assuming that their rational behavior is directed to maximizing the net 
present value of their investments. For this reason, we build upon the work by Bersani et al. [6] because they adopt a similar perspective, although for hydrogen distribution. In order to formulate the decision problem for $\mathrm{CNG}$ in FVG, following assumptions are introduced:

- Based on previous break-even analysis, we assumed that in the municipalities characterized by the presence of gas pipeline only HP stations should be built;

- The location of the three existing CNG stations is fixed, but their costs are treated from an external viewpoint like the costs of new stations;

- At the moment, it is not realistic to allow the construction of more than one CNG station in each municipality.

\subsection{Model Structure}

The basic variables of the models are defined as follows:

$y_{i}, i=1, \ldots ., N$ : binary variable associated with the $i$ th municipality. Specifically, $y_{i}=1$ when a station is located in the ith considered municipality, otherwise $y_{i}=0$;

$y_{a i}, i=1, \ldots, N$ : binary variable associated with the $i$ th municipality, with $\mathrm{y}_{\mathrm{ai}}=1$ if a HP CNG station is located in the considered municipality, otherwise $y_{a i}=0$; $y_{b i}, i=1, \ldots ., N$ : binary variable associated with the $i$ th municipality, with $\mathrm{y}_{\mathrm{bi}}=1$ if a LP CNG station is located in the considered municipality, otherwise $y_{b i}=0$ $Q_{i}$ : capacity of the $i$ th fuel station in $\mathrm{kNm}^{3} /$ year;

$P_{i}$ : annual equivalent profit of the $i$ th station, in $€ /$ year

$x_{i j}$ : binary variable representing the fraction of demand associated with the $j$ th municipality to be served by a fuel station located in the $i$ th municipality.

The parameter $D_{i}$ represents the CNG demand in each municipality, calculated according to Eq. (1) using the estimated number of CNG vehicles in the $i$ th municipality as independent variable. $V_{i}$ is calculated by multiplying the total number of vehicles in the municipality, which is known for the year 2009, by the share of CNG vehicles on total vehicles in 2009, which is known at province level. Other relevant parameters are the binary parameter $p_{i}$, equaling 1 if the $i$ th municipality is served by a gas pipeline, 0 otherwise, and the distance $t_{i j}$ between municipalities $i$ and $j$. The objective function is to maximize the sum of annual equivalent profits of all stations, as shown in Eq. (3):

$$
\operatorname{Max} \sum_{i=1}^{N} P_{i}=\left\{\sum_{i=1}^{N}\left[\begin{array}{l}
p_{C N G} \cdot Q_{i}-C_{C N G} Q_{i}-C_{H R} y_{i}+ \\
-\left(C_{M A I N, H P}+C_{E L, H P}\right) Q_{a i}-\left(C_{M A I N, L P}+C_{E L, L P}\right) Q_{b i}- \\
f \cdot\left(C_{S T R F, H P} y_{a i}+C_{S T R V, H P} Q_{a i}+C_{S T R F, L P} y_{b i}+C_{S T R V, H P} Q_{b i}\right)
\end{array}\right]\right\}
$$


Where $f$ is the capital recovery factor of a series of uniform amounts, in this case for an interest rate of $7 \%$ for 15 years, while other cost and sale price parameters are summarized in Appendix.

All cost functions are obtained interpolating data obtained by CNG station constructors or managers for at least three different plant capacities.

It should be observed that purchase and sale prices of natural gas obviously do not depend on connection technology, while the cost of human resources for capacities within the technically acceptable range is invariant.

Equations (4-13) represent the main constraints of the model, basically aimed at determining the capacity $Q_{i}$ of the service station located in the $i$ th municipality according to Eq. (5) as a weighted sum of demand in the municipality of concern and of demand in other municipalities, which can be partially diverted to the $i$ th station depending on attraction factors (Eq. 7) related to distance decay functions (Eq. 8) as indicated in [9] and in [6]. With respect to those references, we do not fix a minimum number of stations, as it is our aim to find it through system optimization. On the other hand, the truncation condition we introduce with Eq. (7) influences the relative distance between stations, in that it imposes that, above a maximum distance $t_{\max }$, the attraction of customers to the fuel station drops to zero.

$$
\begin{aligned}
& Q_{i}=\sum_{\substack{j=1 \\
i \neq j}}^{N} x_{i j} D_{j}+D_{i} y_{i} \quad i=1, \cdots, N \\
& x_{i j}=\left\{\begin{array}{cl}
\frac{a t r_{j i} \cdot y_{i}\left(1-y_{j}\right)}{\sum_{i=1}^{N} a t t r_{j i} \cdot y_{i}} & t_{i j} \leq t_{\max } \\
0 & t_{i j}>t_{\max } \quad i=1, \cdots, N \quad j=1, \cdots, N
\end{array}\right. \\
& \operatorname{attr}_{j i}=\frac{1}{t_{j i}} \quad i=1, \cdots, N \quad j=1, \cdots, N \\
& y_{a i}+y_{b i} \leq y_{i} \quad i=1, \cdots, N \\
& y_{a i} \leq p_{i} \quad i=1, \cdots, N \\
& y_{b i} \leq 1-p_{i} \quad i=1, \cdots, N \\
& Q_{a i} \leq y_{a i} B_{H P} \quad i=1, \cdots, N \\
& Q_{b i} \leq y_{b i} B_{L P} \quad i=1, \cdots, N \\
& Q_{a i}+Q_{b i}=Q_{i} \quad i=1, \cdots, N \\
& P_{i} \geq 0 \quad i=1, \cdots, N
\end{aligned}
$$

Equations (7-12) deal with HP-LP factors and express logical conditions, requiring that at maximum one station is built in each municipality, either HP or 
LP (Eq. 7) and in particular assuring that HP technology is used if we choose to construct stations in municipalities served by HP natural gas pipeline (Eqs. 8 and 9). A maximum technically feasible capacity $B$ equaling $2000 \mathrm{kNm}^{3} /$ year is imposed through Eqs. (10) and (11) which at the same time force the system to install either HP capacity $Q_{a i}$ or LP capacity $Q_{b i}$, so that the total capacity calculated with Eq. (12) is actually either equal to $Q_{a i}$ if HP is technically feasible or to $Q_{b i}$ otherwise. Finally, Eq. (13) requires the equivalent annual profit of every single station to be non negative

\subsection{Model Implementation}

Like similar models in literature, the model is structured as a MINLP problem with binary and continuous decision variables. After a preliminary screening, mainly excluding low population municipalities in the mountain part of the region, 219 eligible locations were identified and distances were calculated and saved in Excel format using RouteBlast (2013). The nature and dimensions of the problem make the identification of global optimum solutions within the branch and bound framework very challenging due to the presence of both the integer variables and the non-convexities. For this reason, we decided to try a genetic solver and, given that our data had been mainly been saved in spreadsheet form, we chose to use the commercial solver Evolver ${ }^{\circledR}$ (2010), with 0.5 crossover rate, a mutation rate automatically determined by the program and a stopping rule entailing a progress of $10 \%$ in the last 1500 trials and a maximum of 15000 trials. Solution times between 10 and $30 \mathrm{~h}$ were achieved with these settings and considered acceptable for our purposes.

\section{Results and Discussion}

In order to asses potential effects of different subsidy schemes, optimal location and capacities were evaluated in four scenarios, i.e.:

- At current demand levels, with no subsidies;

- At current demand levels, with the $50 \%$ capital grant foreseen by the regional government;

- With double demand level in the border area, with no capital grants to stations;

- With double demand level in the border area and $50 \%$ capital grant.

By evaluating these scenarios at different levels of the truncation factor introduced with Eq. (6), we found that such factor has a significant impact on the share of total demand, which is cost-effectively served by stations and on their location and size. The analysis were conducted for two values of $t_{\max }$, namely 20 and 
$50 \mathrm{~km}$, representing the maximum daily distance for $80 \%$ of European drivers and the maximum daily distance for $70 \%$ of Italian drivers respectively [21].

The analysis with $t_{\max }$ at $20 \mathrm{~km}$ seem to give a more realistic picture of the current scenario, in that it leads to conclude that only four stations would be sustainable at current conditions with no subsidies, whereas the analysis at $t_{\max }=50 \mathrm{~km}$ tells that even six stations would be viable without incentives. On the other hand, the evaluation of the effect of subsidies seems more realistic with the $50 \mathrm{~km}$ analysis, because the other one foresees a proliferation of up to 12 micro-plants with an average capacity of less than $200 \mathrm{kNm}^{3} /$ year, which does not seem a rational behavior for investors given, in particular, that average sales at national level can be estimated at about $940 \mathrm{kNm}^{3} /$ year per station. To this respect, from our evaluation with both the 20 and $50 \mathrm{~km}$ an average plant capacity of $350 \mathrm{kNm}^{3} /$ year is already viable at the financial conditions we assume (i.e. $7 \%$ interest rate for 15 years. Post-analysis discussion with constructors who provided cost data pointed out that, based on experience, a minimum size of about $500 \mathrm{kNm}^{3} /$ year should be economically feasible. This size is smaller than the national sales average, probably due to the more recent practice of upgrading existing gasoline refueling stations-which requires less investment-rather than building standalone stations selling CNG only, which was common practice in the 1990s due to competition and legislation barriers. On the other hand, what we probably underestimated are contingencies, variability in connection costs and the minimum attractive rate of return, which is actually considered by investors to account for those risks. We intend to continue our analysis on these aspects, e.g. by extended sensitivity analysis. Nevertheless, we conclude that at the moment the $50 \mathrm{~km}$ scenario is the more realistic and the only one we choose to graphically represent in this chapter (see Fig. 2), for the sake of brevity.

Looking at Fig. 2 we find that a generic $50 \%$ subsidy at current demand conditions would still lead entrepreneurs to choose locations far away from the border, in spite of competition due to relative proximity of existing CNG stations, rather than to invest in the F1 area. A similar pattern was also obtained in the $20 \mathrm{~km}$ scenario. As a consequence, the small demand by about 200 vehicles registered in the $\mathrm{F} 1$ area, probably in past times of substantial national incentives for CNG vehicle purchase, is not met and at present those vehicles are most likely fuelled with gasoline. Moreover, the more realistic $50 \mathrm{~km}$ analysis shows that the $50 \%$ subsidy, which, based on our optimization, would result in an outlay of almost $1 \mathrm{M} €$ for the regional government, would not substantially change the number of economically viable CNG stations (from 6 to 7), although it would certainly help these investment opportunities to be put into action at these times of difficult access to credit for firms. Still, if the aim of the regional government is to attain a more even distribution of CNG demand in the region, specific measures for the F1 area are needed. For instance, increasing the number of vehicles in the F1 by $100 \%$, for instance through capital grants for vehicle purchase, would make a fuel station feasible there (although with our probably optimistic minimum capacity). And probably the most effective option would be to invest in both 


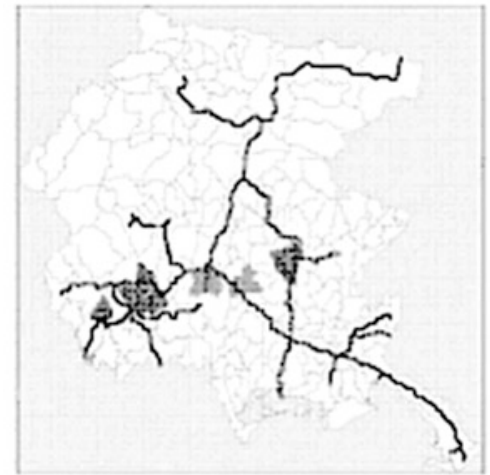

Currem demand, no subsidjes

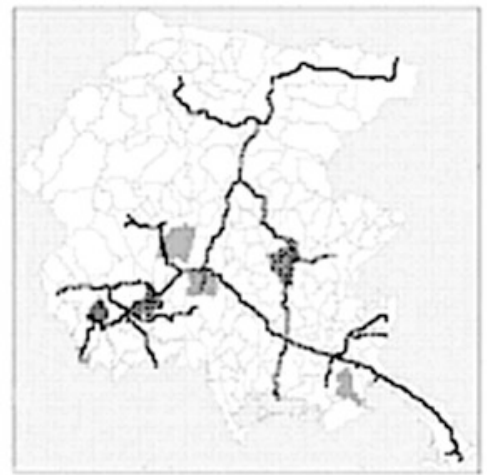

Incrcased demand in $\mathrm{Fl}$, no subsidics

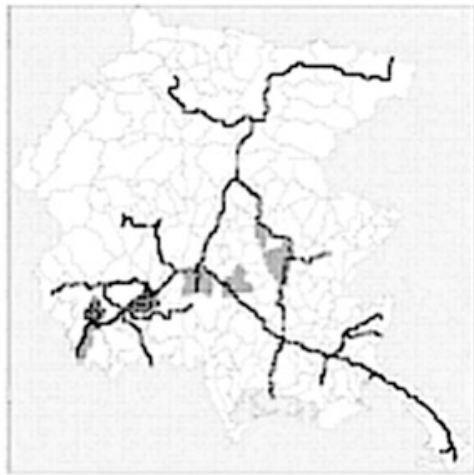

Curreat demand. 50\% capital grant

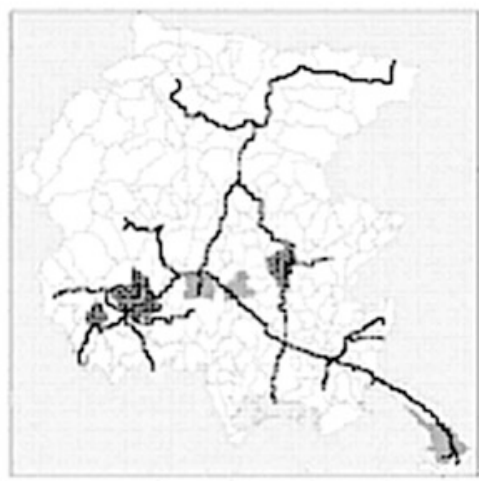

Increasod denaed in F1, SOF capital grant

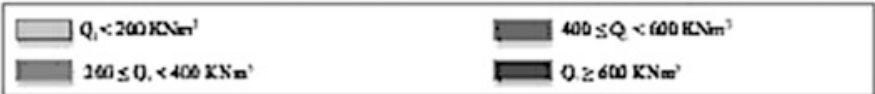

Fig. 2 Optimized capacity and location of CNG refueling station, with $\mathrm{t}_{\max }=50 \mathrm{~km}$

vehicle subsidies and station subsidies (lower right quarter of Fig. 2). In our view, however, in present times of public outlay restriction, incentives should be specifically targeted to current low demand areas, especially F1.

\section{Conclusions}

Like every model, the presented MINLP optimization model for CNG refueling stations planning in Friuli Venezia Giulia is based on assumptions and simplifications, in part due to computational requirements and in part depending on the features of available data. Collecting further information through empirical 
research would be a necessary step to increase the validity of the obtained results. In particular, given the demonstrated effect of the attraction function, data collection of actual or stated refueling behavior of $\mathrm{CNG}$ vehicle drivers would be needed, given that empirical research on refueling behavior, on which modeling assumptions of this and similar models in literature are based, dates back to the 1980s [11], is focused on gasoline and on the US market. So far, the developed model supported reasonable arguments to rethink the structure of public subsidies making government goals more explicit. Finally, the analysis and statistical modeling of demand data for this case study shows that different policies and tariff structures of neighboring countries impact on consumers' decisions of vehicle purchase, and consequently on alternative fuel demand, which may jeopardize the effects of policies for sustainable transport put into force in single countries. From an European perspective, efforts on policy and infrastructure development could therefore benefit from international coordination, perhaps more than from competition.

\section{Appendix A}

Table A.1 Annual LPG demand at province level

\begin{tabular}{|c|c|c|c|c|c|}
\hline Year & $\begin{array}{l}\mathrm{P}_{\mathrm{lpg}} \\
\text { (euro/l) }\end{array}$ & Province & $\begin{array}{l}\mathrm{D}(\mathrm{PROV}) \\
\text { (1) }\end{array}$ & Vehicles $_{\text {lpg }}(\mathrm{PROV})$ & Vehicles $_{\text {TOT }}(\mathrm{PROV})$ \\
\hline \multirow[t]{4}{*}{2007} & 0.626 & Gorizia & 81810 & 271 & 88812 \\
\hline & 0.626 & Pordenone & 2097972 & 3562 & 193833 \\
\hline & 0.626 & Trieste & NA & 409 & 127548 \\
\hline & 0.626 & Udine & 3616002 & 2679 & 337664 \\
\hline \multirow[t]{4}{*}{2008} & 0.680 & Gorizia & 136.50 & 371 & 8562 \\
\hline & 0.680 & Pordenone & 3950514 & 4079 & 196487 \\
\hline & 0.680 & Trieste & NA & 595 & 127591 \\
\hline & 0.680 & Udine & 4177764 & 3297 & 341432 \\
\hline \multirow[t]{4}{*}{2009} & 0.563 & Gorizia & 141.804 & 724 & 88598 \\
\hline & 0.563 & Pordenone & 4488642 & 5781 & 198013 \\
\hline & 0.563 & Trieste & NA & 1018 & 127670 \\
\hline & 0.563 & Udine & 4915872 & 5571 & 344248 \\
\hline \multirow[t]{4}{*}{2010} & 0.661 & Gorizia & 545400 & 953 & 88501 \\
\hline & 0.661 & Pordenone & 6655698 & 6.903 & 199270 \\
\hline & 0.661 & Trieste & NA & 1284 & 127842 \\
\hline & 0.661 & Udine & 7419258 & 6986 & 347507 \\
\hline \multirow[t]{4}{*}{2011} & 0.755 & Gorizia & 621756 & 982 & 88636 \\
\hline & 0.755 & Pordenone & 7850124 & 6914 & 201975 \\
\hline & 0.755 & Trieste & NA & 1321 & 128006 \\
\hline & 0.755 & Udine & 7010208 & 7068 & 351215 \\
\hline
\end{tabular}


Table A.2 Economic coefficients

\begin{tabular}{lll}
\hline & High-pressure & Low-pressure \\
\hline $\mathrm{C}_{\mathrm{STRV}}\left[€ / \mathrm{kNM}^{3}\right.$ year $]$ & 287.8 & 413.5 \\
$\mathrm{C}_{\mathrm{STRF}}[€ /$ year $]$ & 249811 & 255996 \\
$\mathrm{C}_{\mathrm{EL}}\left[€ / \mathrm{kNM}^{3}\right]$ & 15.21 & 28.21 \\
$\mathrm{C}_{\mathrm{MAIN}}\left[€ / \mathrm{kNM}^{3}\right.$ year $]$ & $0.402\left(\mathrm{C}_{\mathrm{STRF}} \mathrm{y}_{\mathrm{i}}+\mathrm{C}_{\mathrm{STRV}} \mathrm{Q}_{\mathrm{i}}\right)-139930$ & $0.269\left(\mathrm{C}_{\mathrm{STRF}} \mathrm{y}_{\mathrm{i}}+\mathrm{C}_{\mathrm{STRV}} \mathrm{Q}_{\mathrm{i}}\right)-106840$ \\
$\mathrm{C}_{\mathrm{CNG}}\left[€ / \mathrm{kNM}^{3}\right]$ & 490 & 490 \\
$\mathrm{C}_{\mathrm{HR}}[€ /$ year $]$ & 35180 & 35180 \\
$\mathrm{P}_{\mathrm{CNG}}\left[€ / \mathrm{kNM}^{3}\right]$ & 980 & 980 \\
\hline
\end{tabular}

\section{References}

1. Yeh, S.: An empirical analysis on the adoption of alternative fuel vehicles: the case of natural gas vehicle. Energy Policy (Elsevier) 35(11), 585-5875 (2007)

2. Collantes, G., Melaina, M.W.: The co-evolution of alternative fuel infrastructure and vehicles: a study of the experience of Argentina with compressed natural gas. Energy policy 39, 664-665 (2011)

3. Struben, J., Sterman, J.D.: Transition challenges for alternative fuel vehicle and transportation systems. Environ. Plann. B 35, 1070-1097 (2008)

4. Kuby, M., Lim, S.: The flow-refueling location problem for alternative-fuel vehicles stochastic modeling. Socio Econ. Plann. Sci. 39(2), 125-145 (2005)

5. Lin, Z., Ogden, J., Fan, Y., Chen, C.W.: The fuel-travel-back approach to hydrogen station siting. Int. J. Hydrogen Energy 33, 3096-3101 (2008)

6. Bersani, C., Minciardi, R., Sacile, R., Trasforini, E.: Network planning of fuelling service stations in a near-term competitive scenario of the hydrogen economy. Econ. Plann. Sci. 43, 55-71 (2002)

7. Kuby, M., Lines, L., Schultz, R., Xie, Z., KiM, J.G., Lim, S.: Optimization of hydrogen stations in Florida using the flow-refueling location model. Int. J. Hydrogen Energy 34, 6045-6064 (2009)

8. Stephens-Romero, S., Brown, T., Kang, J., Recker, W., Samuelsen, G.S.: Systematic planning to optimize investments in hydrogen infrastructure deployment. Int. J. Hydrogen Energy 35, 4652-4667 (2010)

9. Frick, M., Axhausen, K.W., Carle, G., Wokaun, A.: Optimization of the distribution of compressed natural gas $(\mathrm{CNG})$ refueling station: swiss case studies. Transp. Res. Part D 12, 10-22 (2007)

10. Upchurch, C., Kuby, M., Lim, S.: A model for location of capacitated alternative-fuel stations. Geogr. Anal. 41, 133-144 (2009)

11. Kitamura, R., Sperling, D.: Refueling behavior of automobile drivers. Transp. Res. Part A 21, 235-245 (1987)

12. Bapna, R., Thakur, L.S., Nair, S.K.: Infrastructure development for conversion to environmentally friendly fuel. Eur. J. Oper. Res. 33, 480-496 (2002)

13. Sabio, N., Gadalla, M., Guillen-Gosalbez, G., Jimenez, L.: Strategic planning with risk control of hydrogen supply chains for vehicle use under uncertainty in operating costs: a case study of Spain. Int. J. Hydrogen Energy 35, 6836-6852 (2010)

14. Brey, J.J., Carazo, A.F., Brey, R.: Using AHP and binary integer programming to optimize the initial distribution of Hydrogen infrastructures in Andalusia. Hydrogen Energy Publication 37, 5372-5384 (2011) 
15. Hugo, A., Ruttera, P., Pistikopoulosa, S., Amorellib, A., Zoia, G.: Hydrogen infrastructure strategic planning using multi-objective optimization. Int. J. Hydrogen Energy 30, 1523-1534 (2005)

16. Aci: Annuario statistico dell'Automobile Club d'Italia (2012)

17. GVR (2013), Gas Vehicle Report, 135(12), 25-27

18. Figisc: Le vendite di benzina e metano in Friuli Venezia Giulia 2007-2011 (analisidefinitiva) (2011)

19. Sterner T., Dahl C.A. (1991).Modeling transport fuel demand. In: Sterner, T. (ed.) International Energy Economics 13(3), 203-210

20. Dahl, C.A.: Measuring global gasoline and diesel price and income elasticities. Energy Policy 41, 2-13 (2011)

21. JRC: Driving and parking patterns of European car drivers: a mobility survey (2012) 